\title{
Clinical Image:
}

Carpal Tunnel Biopsy identifying Transthyretin Amyloidosis

Taryn Youngstein MD $1 *{ }^{(}$, Janet A Gilbertson CSci FIMBS 1, David F Hutt B App

Sci 1, Mark RE Coyne PhD 1, Tamer Rezk MD 1, Richa Manwani MD 1, Huw

Beynon MD 2, Candida C Quarta PhD 1, Helen J Lachmann PhD 1, Julian D

Gillmore PhD 1, Nicholas Goddard MD 3, Philip N Hawkins PhD FMedSci 1

1 National Amyloidosis Centre, UCL Division of Medicine, London

2 Department of Rheumatology, Royal Free Hospital, London

3 Department of Orthopedics, Royal Free Hospital, London

* Corresponding Author:

Dr Taryn Youngstein, National Amyloidosis Centre, UCL Division of Medicine, Rowland Hill Street, London, UK, NW3 2PF

Telephone number: +44 207433 2763, Fax number: +44 2074332817

Email: t.youngstein@ucl.ac.uk

This article has been accepted for publication and undergone full peer review but has not been through the copyediting, typesetting, pagination and proofreading process which may lead to differences between this version and the Version of Record. Please cite this article as an 'Accepted Article', doi: 10.1002/art.40162

(C) 2017 American College of Rheumatology

Received: Mar 31, 2017; Accepted: May 23, 2017 
Disclosures and conflicts of interest: No author declares disclosures relevant for the manuscript or any conflict of interest or potential conflict of interest.

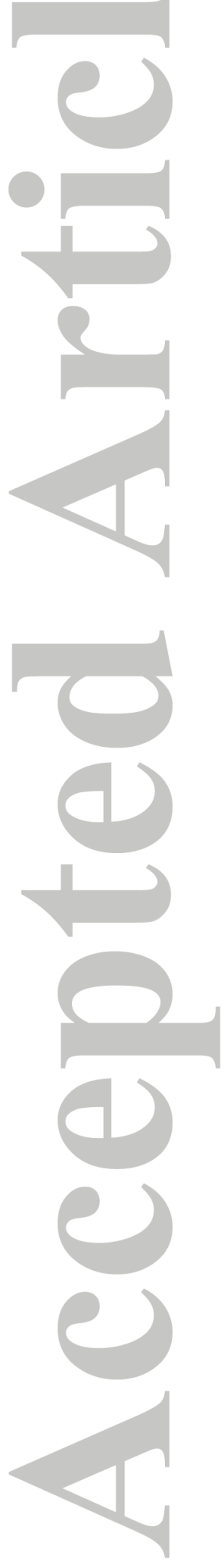

John Wiley \& Sons

This article is protected by copyright. All rights reserved. 
An 86 year-old woman underwent routine decompression for carpal tunnel syndrome following which a sample of tenosynovium was examined histologically. Amyloid deposits were identified on Congo red staining viewed under fluorescent light (A). Immunohistochemical staining confirmed that the amyloid deposits were transthyretin (TTR) type. She was referred to the National Amyloidosis Centre for further evaluation where she described a recent hospital admission for unexplained dyspnoea. Echocardiography showed normal systolic function, but a thickened intraventricular septum along with impaired global strain rate of $-15.7 \%$ and a strain pattern consistent with cardiac amyloidosis. ${ }^{99 m}$ Technetium-3,3-diphosphono-1,2propanodicarboxylic acid $\left({ }^{99 m}\right.$ Tc-DPD) scintigraphy revealed Perugini grade 2 uptake of tracer in her heart (B). Gene sequencing revealed no mutations in the transthyretin gene. A diagnosis of wild type ATTR amyloidosis (ATTRwt) was made.

Carpal tunnel syndrome is a common early clinical manifestation of wild-type transthyretin amyloidosis, also known as senile systemic or cardiac amyloidosis. Among patients with cardiac ATTRwt amyloidosis attending our centre, $98 \%$ have had evidence of median nerve entrapment on neurophysiological studies and $48 \%$ have had a history of carpal tunnel decompression as much as 12 years prior to their typical presentation with advanced heart failure symptoms.

Cardiac ATTRwt amyloidosis is currently diagnosed in only about 150 individuals in the UK each year, but post-mortem studies indicate that ATTRwt amyloid deposits are actually present in up to $30 \%$ of males over 80 years (1). Repurposing of ${ }^{99 m}$ Tc-DPD bone scintigraphy largely abrogates the need for diagnostic cardiac biopsy, showing substantial cardiac uptake in nearly all cases (2). 
Carpal tunnel biopsy can readily identify ATTR amyloid deposition and may identify individuals at risk of developing cardiac ATTR amyloidosis, for which specific therapies are now in clinical trial (3).

1. Pinney JH, Whelan CJ, Petrie A, Dungu J, Banypersad SM, Sattianayagam P, et al. Senile systemic amyloidosis: clinical features at presentation and outcome. Journal of the American Heart Association. 2013;2(2):e000098.

2. Gillmore JD, Maurer MS, Falk RH, Merlini G, Damy T, Dispenzieri A, et al. Nonbiopsy Diagnosis of Cardiac Transthyretin Amyloidosis. Circulation. 2016;133(24):2404-12.

3. Hawkins PN, Ando Y, Dispenzeri A, Gonzalez-Duarte A, Adams D, Suhr OB. Evolving landscape in the management of transthyretin amyloidosis. Annals of medicine. 2015;47(8):625-38.

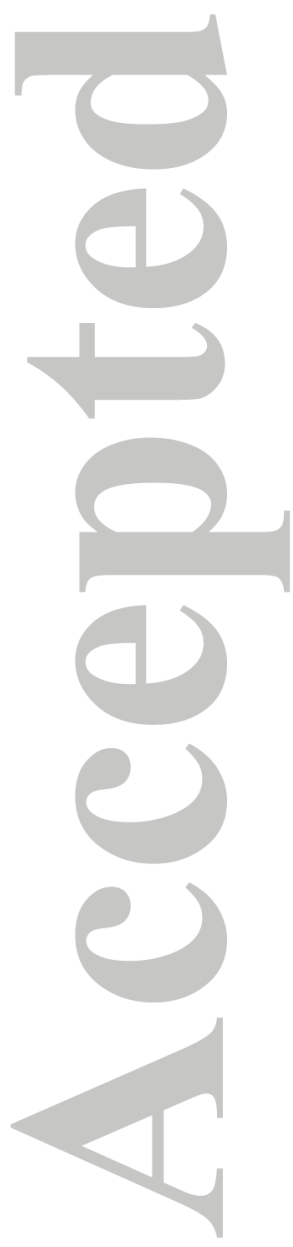




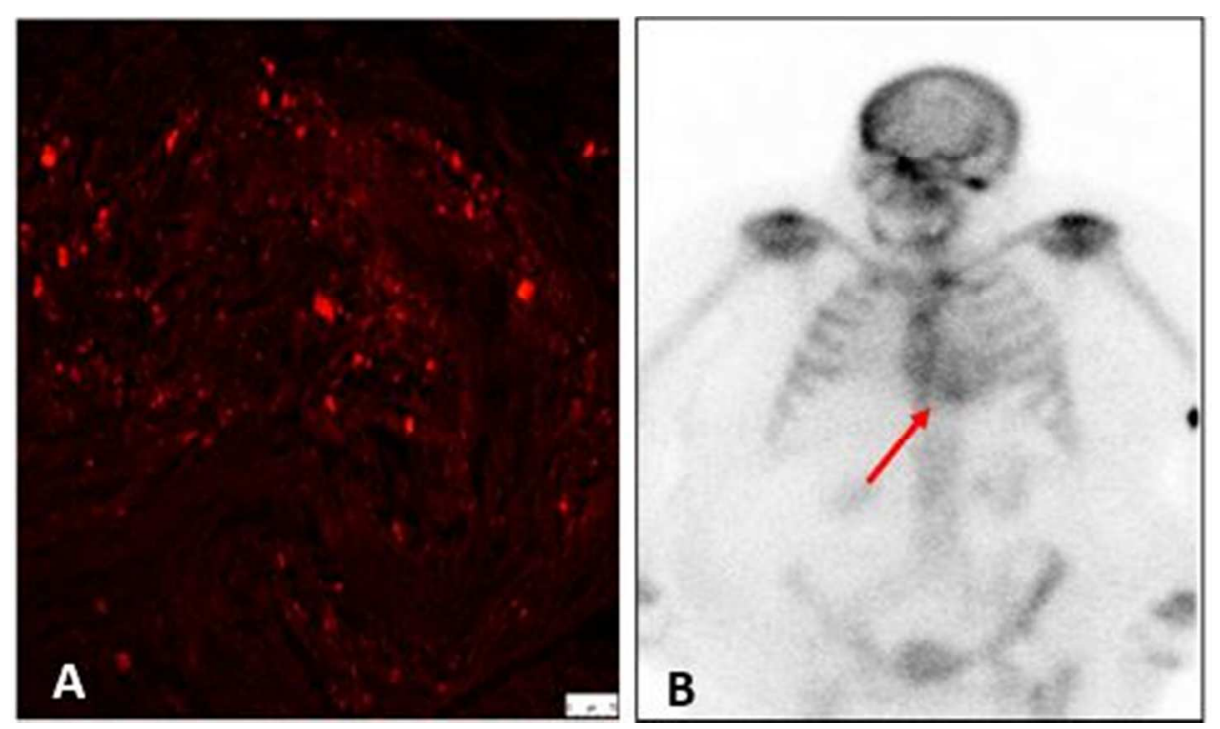

The word document contains the Title and legend as this is a clinical image for submission.

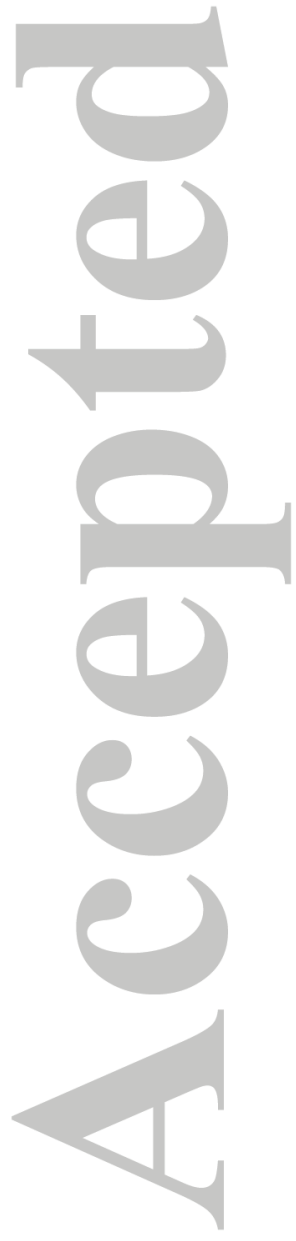

John Wiley \& Sons

This article is protected by copyright. All rights reserved. 